\title{
SOSIALISASI PENGOPERASIAN MICROSOFT EXCEL UNTUK ADMINISTRASI DATA MATEMATIS PADA KARANG TARUNA
}

\author{
Siti Julaeha, Somawati \\ Informatika, Fakultas Teknik dan Ilmu Komputer, Universitas Indraprasta PGRI \\ Jl. Raya Tengah no.80, Gedong, Pasar Rebo, Jakarta, Indonesia
}

\begin{abstract}
Abstrak
Pemanfaatan media teknologi terutama Microsoft Excel tidak hanya digunakan di perkantoran dan akademisi saja tetapi dalam sosialisasi di dalam karang taruna sangat membantu dalam pengolahan angka yang menggunakan spreadsheet yang terdiri dari baris dan kolom data. Pemuda karang taruna yang secara langsung dapat dikreasikan ke dalam bentuk pendataan administrasi matematis dimana banyak pengguna aplikasi Microsoft Excel ini yang memanfaatkan untuk menyampaikan sebagai media komunikasi, dari pemberi informasi ke penerima informasi. Sebagai tujuan pemberdayaan pemuda karang taruna maka kami berupaya memberikan solusi untuk memperkuat potensi atau daya yang dimiliki oleh pemuda karang taruna meliputi langkah-langkah nyata yang menyangkut penyediaan berbagai peluang yang dapat membuat pemuda karang taruna menjadi semakin berdaya, kreatif, dan inovatif melalui penggunaan Microsoft Excel. Kemudian untuk selanjutnya dapat dikembangkan dan diaplikasikan sesuai dengan ide-ide yang dimiliki pemuda karang taruna sehingga kami dapat menciptakan suasana yang memungkinkan potensi pengurus, anggota maupun pemuda-pemudi yang terlibat dalam karang taruna berkembang dimana tidak ada pemuda yang sama sekali tanpa daya, mendorong, memotivasi, dan membangkitkan kesadaran akan potensi yang dimiliki serta upaya untuk mengembangkannya.
\end{abstract}

Kata Kunci : Microsoft Excel, Karang Taruna, Administrasi Data Matematis

\begin{abstract}
Utilization of media technologies especially Microsoft Excel not only used in the Office and academics but in socialization in karang taruna are helpful in processing numbers using spreadsheet that consists of rows and columns the data. Youth the karang taruna directly can be dikreasikan into the form of a mathematical administrative logging where many users of this Microsoft Excel applications that utilize to convey as a communication medium, from information to recipient of the information. As the purpose of youth empowerment coral midshipman then we strive to provide solutions to strengthen the potential or power possessed by the youth group of coral covering the real measures that concern the provision of a wide range of opportunities that can create Coral youth cadets become increasingly empowered, creative, and innovative through the use of Microsoft Excel. Then henceforth can be developed and applied in accordance with the ideas of youth-owned coral midshipman so we can create an atmosphere that allows potential Trustees, members or young adults have engaged in coral Midshipman flourish where there is no youth who is totally without power, encourage, motivate, and raised awareness of the potential, as well as efforts to develop it.
\end{abstract}

Keywords: Microsoft Excel, Coral Midshipman, Mathematical Data Administration

Correspondence author: Siti Julaeha, nyooi.sholeha@gmail.com, Jakarta, Indonesia 


\section{PENDAHULUAN}

Dengan berkembangan teknologi yang pesat maka dibutuhkan sumber daya manusia yang mampu mengelola serta memanfaatkannya dengan baik (Prasetyo, Yunarso, \& Nugroho, 2014). Salah satu sumber daya manusia yang perlu mendapatkan perhatian adalah generasi muda (Sulasmoro, Afriliana, \& Bukhari, 2017). Generasi muda selalu menjadi bagian yang penting dalam pembangunan bangsa dan negara (Irianto \& Febrianti, 2017). Sebagai salah satu wadah berkumpulnya generasi muda, karang taruna layak mendapatkan prioritas utama dalam pembangunan bangsa. Karena karang taruna adalah organisasi sosial wadah pengembangan generasi muda yang tumbuh dan berkembang atas dasar kesadaran dan tanggung jawab sosial dari, oleh dan untuk masyarakat terutama generasi muda di wilayah desa/kelurahan. Seperti halnya karang taruna di wilayah kecamatan Jatisampurna RT.01 RW. 05 yang bergerak di bidang usaha kesejahteraan sosial untuk lingkungannya.

Terlepas dari betapa pentingnya karang taruna di wilayah kecamatan Jatisampurna RT.01 RW. 05 dalam kesejahteraan sosial lingkungannya tidak dipungkiri bahwa generasi muda karang taruna masih banyak yang belum memanfaatkan teknologi secara maksimal dalam mendukung kegiatan keseharian. Walaupun demikian mereka cukup mengikuti perkembangan teknologi hanya saja mereka memanfaatkan kemajuan teknologi masih lebih berfokus pada social media sekedar mencari hiburan seperti bermain facebook, twitter atau hal-hal yang bisa menghibur mereka. Bagaimana manfaat teknologi untuk membantu tugas kesehariannya belum sepenuhnya mereka terapkan. Seperti halnya ketika mereka di tanya bagaimana cara perhitungan mereka dalam laporan keuangan atau perhitungan uang kas karang taruna (Hanum, 2008). Mereka akan menjawab " ya ngitungnya biasa pake kalkulator", dan ketika di tanya lebih lanjut apakah mereka pernah mencoba menghitung dengan bantuan microsoft excel agar laporan keuangan atau perhitungan uang kas lebih rapih, mereka menjawab "tidak pernah dan tidak tahu jika microsoft excel dapat berguna untuk menghitung keuangan". Dari percakapan tersebut dapat dilihat bahwa memang kurangnya pengetahuan generasi muda karang taruna di wilayah kecamatan Jatisampurna RT.01 RW. 05 terhadap perkembangan teknologi terutama dalam bidang komputer pada aplikasi Microsoft Excel.

Microsoft Excel merupakan program aplikasi spreadsheet (lembar kerja elektronik) pengolah data angka dibawah sistem Operasi Windows. Microsoft Excel dapat digunakan untuk menghitung angka-angka, bekerja dengan daftar data, dan menganalisis data-data serta mempresentasikannya kedalam bentuk grafik/diagram. Menyikapi permasalahan yang telah diuraikan di atas dan dalam rangka pengabdian masyarakat, penulis mengajukan proposal pengabdian masyarakat yang berjudul Sosialisasi Pengoperasian Microsoft Excel Untuk Administrasi Data Matematis Pada Karang Taruna RT.01 RW.05 Jatirangon Dan RT.005 RW.010 Lubang Buaya.

\section{METODE PELAKSANAAN}

Metode yang digunakan dalam pengabdian masyarakat ini adalah metode seminar. Metode Seminar adalah suatu kegiatan ilmiah yang dilaksanakan oleh beberapa orang dalam suatu sidang yang berusaha membahas/mengupas masalah-masalah atau hal-hal tertentu dalam rangka mencari jalan memecahkannya atau pedoman pelaksanaannya. Dengan situasi dan kondisi yang ada dalam karang taruna, maka kami menawarkan solusi untuk melakukan tinjauan dan melakukan workshop langsung terhadap para pengurus 
dan anggota karang taruna untuk lebih memahami pemanfaatan media Microsoft Excel serta pelatihan pembuatan data matematis sebagai upaya yang berkualitas, terampil, cerdas, inovatif, berkarakter, serta memiliki kesadaran dan tanggung jawab sosial.

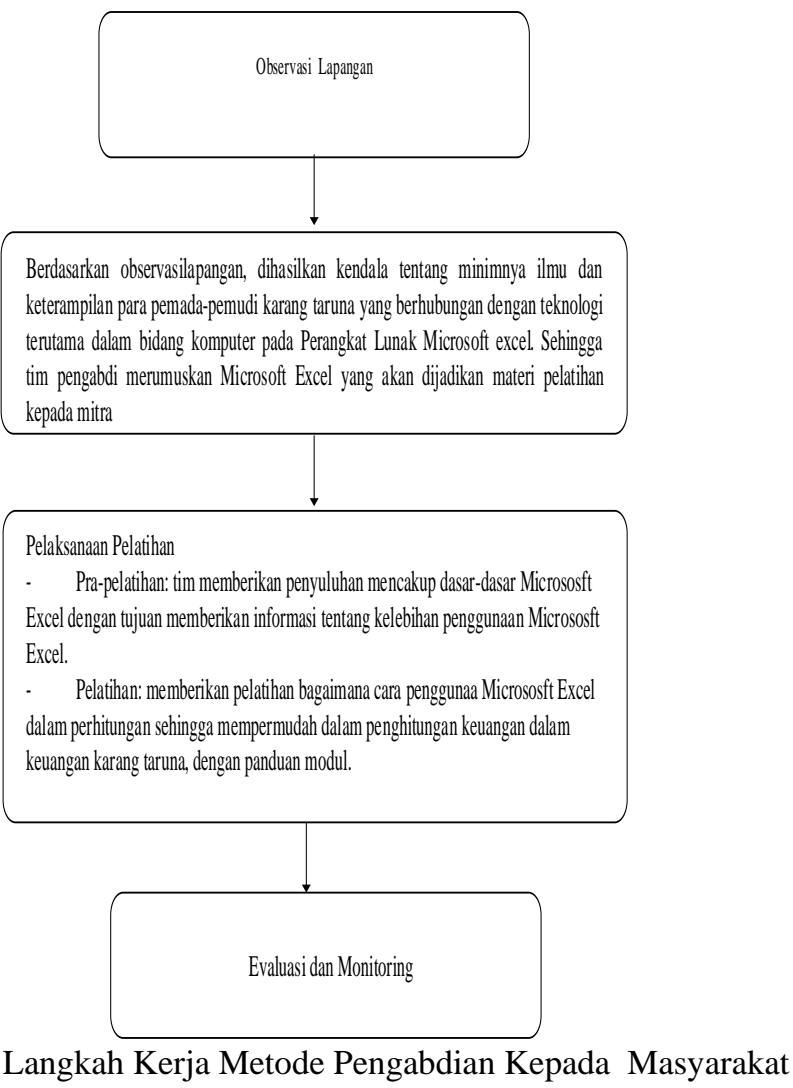

Adapun bahan dan alat yang digunakan dalam kegiatan pelaksanaan pengabdian masyarakat ini yaitu :

1. Modul mengenai pengenalan microsoft excel dan cara mengoprasikan mirosoft excel

2. Proyektor

3. Laptop

4. Internet

5. Software pendukung

\section{HASIL DAN PEMBAHASAN}

Kegiatan pengabdian pada masyarakat yaitu pengoprasian aplikasi Microsoft Excel dalam administrasi data matematis. Kegiatan ini diikuti kurang lebih 15 orang pada karang taruna RT. 01 RW.05 Jatiranggon dan RT. 005 RW. 010 yang merupakan sasaran dalam kegiatan PKM yaitu semua anggota karang taruna.

Adapun langkah-langkah tutorial membuat worksheet di microsoft excel

1. Baris (row) Excel

Baris pada Microsoft Excel mengidentifikasikan sel secara horizontal. Baris Microsoft Excel diidentifikasikan mulai dari baris 1 - 1.048.576, sehingga jumlah baris pada Microsoft Excel adalah 1048576 baris. Anda dapat menuju sel baris terakhir dengan Ctrl+Page Down. 
2. Kolom (column) Excel Kolom pada Microsoft Excel mengidentifikasikan sel secara vertikal. Kolom Microsoft Excel diidentifikasikan mulai huruf A-XFD., sehingga jumlah kolom Microsof Excel adalah 16.384. Anda dapat menuju sel kolom terakhir dengan Ctrl+End

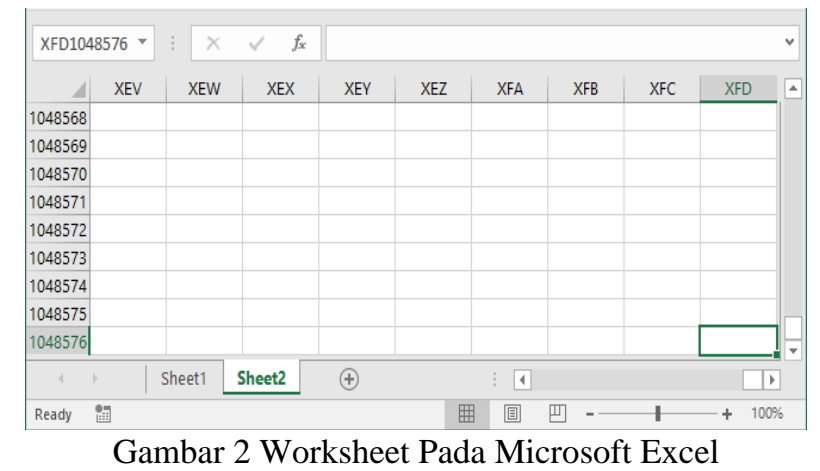

3. Untuk menambah worksheet, dapat dilakukan dengan klik tanda + (plus) pada tab sheet Microsoft Excel. Sedangkan untuk menghapus anda dapat klik kanan nama sheet yang ingin dihapus lalu pilih delete.

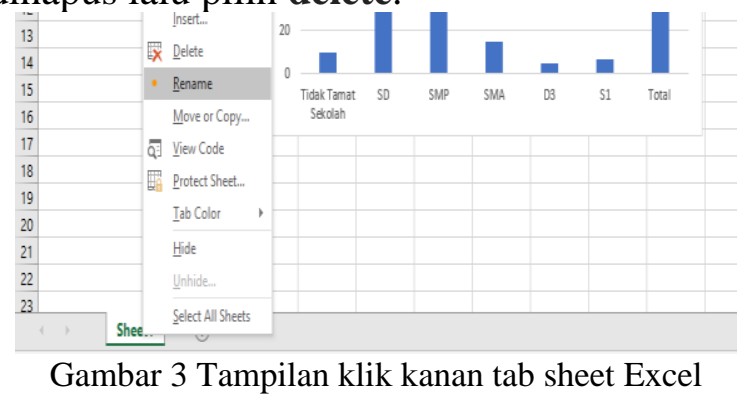

4. Pilihan Klik Kanan Tab Sheet Excel dan terdapat beberapa opsi yang ditampilkan saat pengguna melakukan klik kanan pada tab sheet Microsoft Excel.

a. Insert - Digunakan untuk menambah worksheet baru serta jenis lembar kerja lainnya.

b. Delete - Digunakan untuk menghapus worksheet

c. Rename - Digunakan untuk mengubah nama tab yang disorot

d. Move or Copy - Digunakan untuk mengurutkan worksheet atau menggandakan worksheet

e. View Code - Digunakan untuk menampilkan code Visual Basic / Macro pada worksheet

f. Protect Sheet - Digunakan untuk mengamankan worksheet seperti menambah password

g. Tab color - untuk merubah warna tab yang disorot

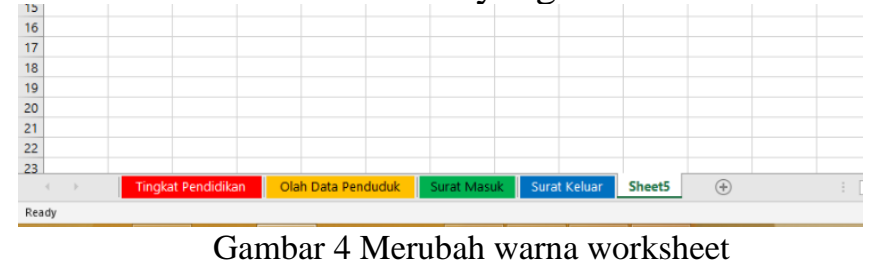

h. Hide - untuk menyembunyikan worksheet, sehingga worksheet tidak muncul pada tab sheet 
i. Unhide - untuk menampilkan kembali worksheet yang disembunyikan

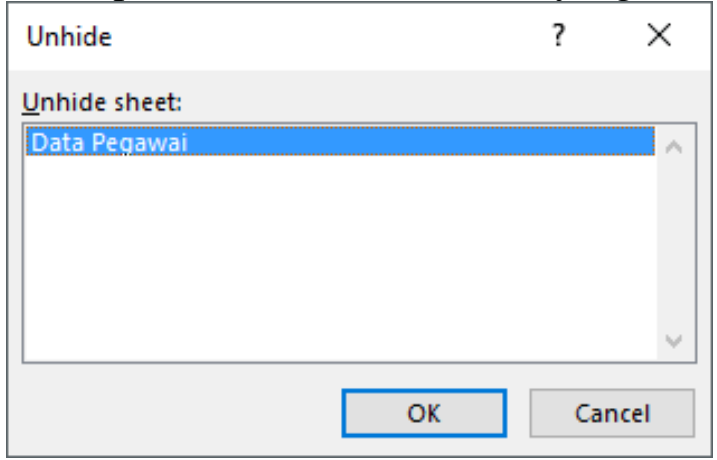

Gambar 5 Menampilkan kembali worksheet yang tidak dimunculkan

j. Select All - untuk memilih semua worksheet dalam workbook aktif. Saat anda bekerja dengan banyak sheet, Microsoft Excel akan mengaktifkan tombol navigasi pada tab sheet untuk berpindah dari worksheet ke worksheet lainnya

Hasil dari kegiatan sosialisasi ini adalah menambah ilmu dan wawasan anggota karang taruna dengan menggunakan laptop. Berdasarkan hasil pelatihan diperoleh bahwa penguasaan pengoprasian microsoft excel dalam administrasi data matematis pada karang taruna RT. 01 RW. 05 Jatiranggon dan RT. 005 RW. 010 Lubang Buaya berjalan efektif. Hal ini dapat dilihat dari peserta yang antusias dalam mengikuti sosialisasi diantaranya banyak peserta yang hadir dalam sosialisasi ini dan kegiatan ini disambut positif oleh pihak karang taruna, ketua RT, ketua RW dan masyarakat yang mengharap kegiatan sosialisasi ini dapat berlangsung seterusnya.

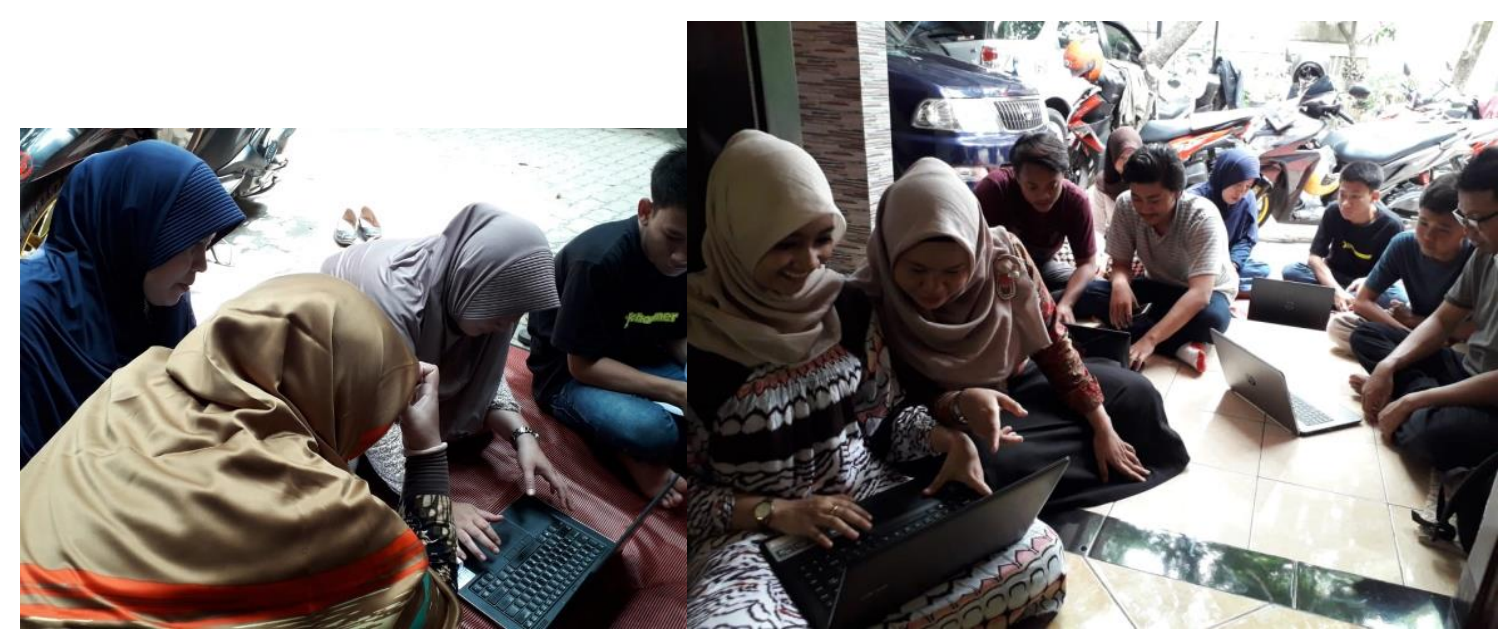

Gambar 6. Kegiatan sosialisasi pada karang taruna RT. 01 RW. 010 Jatiranggon 

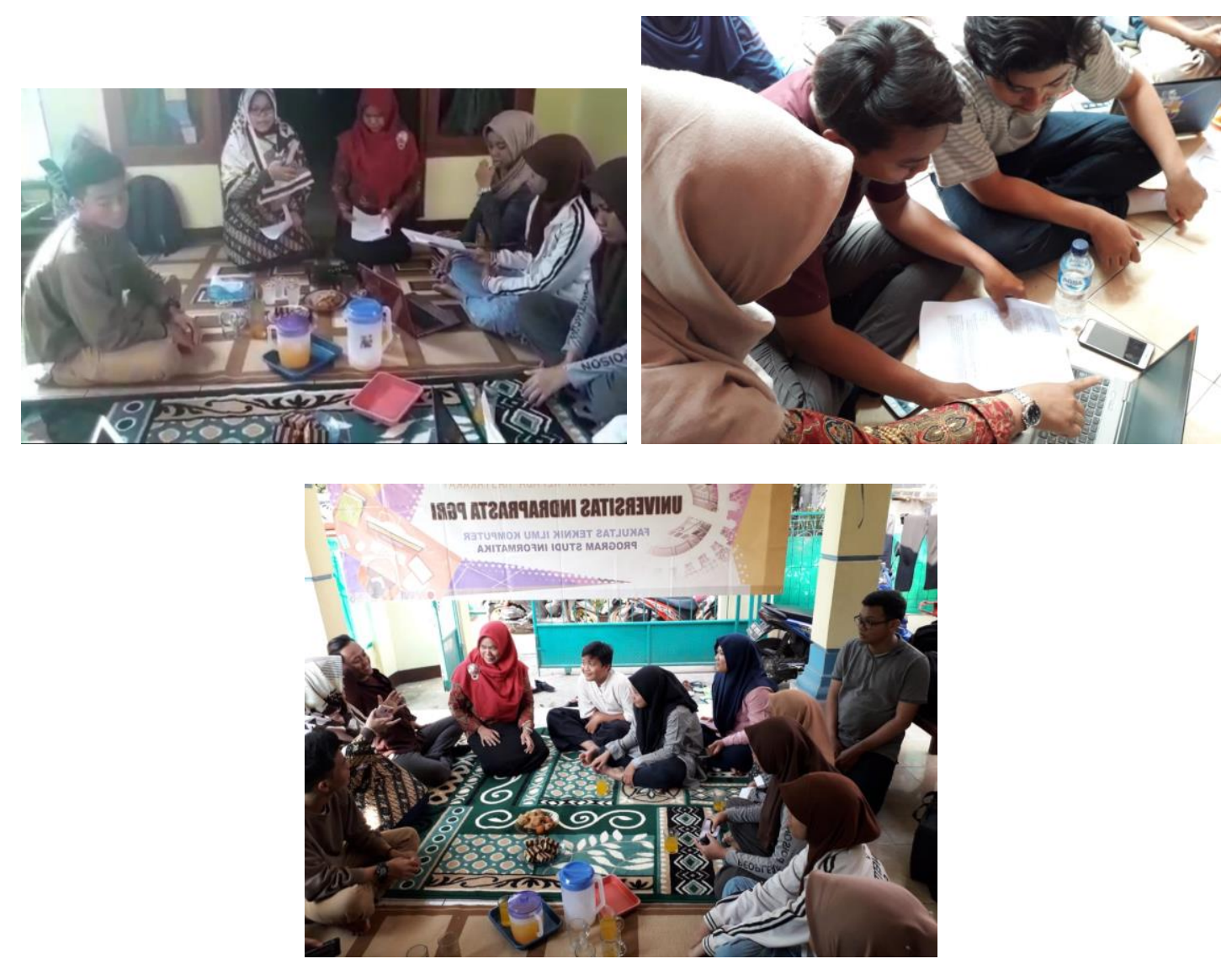

Gambar 7. Kegiatan sosialisasi pada karang taruna RT. 005 RW. 010 Lubang Buaya

\section{SIMPULAN}

Dari hasil pelatihan, diperoleh kesimpulan:

1. Mempermudah karang taruna untuk memahami dan mendalami materi yang diberikan dan berdampak positif pada peningkatan pengetahuan pengurus maupun anggota karang taruna.

2. Mendapatkan pelatihan pengoperasian aplikasi Microsoft Excel sehingga beberapa peserta banyak memiliki kreativitas yang tinggi dalam membuat administrasi data matematis Karang Taruna yang inovatif dapat langsung direalisasikan ke dalam aplikasi Microsoft Excel.

3. Menambah wawasan peserta dengan menggunakan komputer yang tanpa didukung oleh jaringan internet atau mode offline dan aplikasi Microsoft Excel sebagai media pembuatan administrasi data matematis Karang Taruna dan media informasi terhadap sesama anggota karang taruna, pembina, dan aparat desa yang bersangkutan.

Adapun beberapa saran yang diajukan sebagai berikut :

1. Kesiapan pengurus maupun anggota karang taruna dalam menghadapi segala kemajuan teknologi agar tidak menjadi kegagapan teknologi (gaptek) sehingga karang taruna sangat dirasakan manfaatnya oleh lingkungan sekitar.

2. Kesediaan peralatan yang harus lebih memadai, terutama ketersediaan komputer yang kurang dan pengupdatean windows.

3. Kekompakkan antara pengurus karang taruna agar lebih ditingkatkan kembali sehingga mengurangi kesalahpahaman dalam komunikasi. 


\section{DAFTAR PUSTAKA}

Dewi, S. (2007). Komunikasi Bisnis. Andi Offset: Yogyakarta.

Hanum, F. (2008). Penelitian Tindakan Kelas. Diklat Penelitian Tindakan Kelas (PTK) Lanjut Tingkat Nasional Bagi Guru Pamong Belajar, 9-10 Agustus 2008, 1-12. Retrieved from http://staff.uny.ac.id/sites/default/files/tmp/diklat PTK 2008.pdf. Diakses 02 April 2016

Irianto, P. O., \& Febrianti, L. Y. (2017). Pentingnya Penguasaan Literasi bagi Generasi Muda dalam Menghadapi MEA. The 1st Education and Language International Conference Proceedings, 640-647.

kompas. (2014). Pemanfaatan Internet Sebagai Alternatif Sumber Belajar Dan Media Pendidikan Jarak Jauh - KOMPASIANA.com. Retrieved from http://www.kompasiana.com/hariyono21/pemanfaatan-internet-sebagaialternatif-sumber-belajar-dan-media-pendidikan-jarakjauh_55003ff4a33311c271510187

Kristanto, D. dan Triwidodo, T. (2004). Pengembangan Kepribadian Sekretaris. Gramedia: Jakarta.

Permensos 83/HUK/2005 tentang Pedoman Dasar Karang Taruna UU Nomor 40 Th 2009 tentang Kepemudaan Permensos 77 Th 2005 tentang Pedoman Dasar Karang Taruna.

Pranata, D., Hamdani, H., \& Khairina, D. M. (2015). Rancang Bangun Website Jurnal Ilmiah Bidang Komputer (Studi Kasus: Program Studi Ilmu Komputer Universitas Mulawarman). Informatika Mulawarman: Jurnal Ilmiah Ilmu Komputer, 10(2), 25-29.

Prasetyo, H. N., Yunarso, E. W., \& Nugroho, D. H. (2014). Implementasi Sistem Remunerasi Berbasis Kinerja Di Perguruan Tinggi (Studi Kasus Fakultas Ilmu Terapan Universitas Telkom D/H Politeknik Telkom). Prosiding Seminar Nasional Manajemen Teknologi XX, 1(2), 20-29. Retrievedfromhttp://mmt.its.ac.id/download/SEMNAS/SEMNAS XX/MTI/10. Prosiding Hanung NP dan Eka Widhi - Ok.pdf 